\title{
Effects of long-term administration of saturated and n-3 fatty acid-rich diets on lipid utilisation and oxidative stress in rat liver and muscle tissues
}

\author{
Christine Feillet-Coudray $^{1 *}$, Manar Aoun ${ }^{2}$, Gilles Fouret ${ }^{1}$, Béatrice Bonafos ${ }^{1}$, \\ Jeanne Ramos ${ }^{3}$, François Casas ${ }^{1}$, Jean Paul Cristol ${ }^{2}$ and Charles Coudray ${ }^{1}$ \\ ${ }^{1}$ INRA UMR 866, Dynamique Musculaire et Métabolisme, 34060 Montpellier, France \\ ${ }^{2}$ UMR 204 NUTRIPASS IRD/Montpellier-1/Montpellier-2/Supagro, 34000 Montpellier, France \\ ${ }^{3}$ Laboratoire d'Anatomie Pathologique, CHU Gui de Chauliac, 80, Avenue Augustin Fliche, \\ 34295 Montpellier Cedex 5, France \\ (Submitted 19 October 2012 - Final revision received 26 March 2013 - Accepted 26 March 2013 - First published online 9 May 2013)
}

\section{Abstract}

The incidence of metabolic syndrome components including obesity, lipid deregulation, insulin resistance (IR) and non-alcoholic fatty liver disease is increasing rapidly in wealthy societies. The present study was designed to determine the effect of different nutritional lipid patterns (quantity and quality) on lipid utilisation and oxidative stress in the liver and muscle of rats in an integrated fashion. A total of forty-eight Wistar male rats were fed for 12 weeks with a mixed, lard or fish-oil diet, containing either 50 or $300 \mathrm{~g}$ lipid/kg. Rats developed liver steatosis associated with moderate liver injury when fed the $30 \%$ lipid diets, in spite of the absence of overt obesity or IR, except when fed the lard $30 \%$ lipid diet. The intake of the $30 \%$ lipid diets decreased hepatic lipogenesis and mitochondriogenesis and increased lipid peroxidation and protein oxidation. Surprisingly, muscle lipid content was not modified whatever the administered diet. The intake of the $30 \%$ lipid diets increased the muscle protein expression of fatty acid (FA) translocase/cluster of differentiation 36 (FAT/CD36), PPAR $\gamma$ co-activator $1 \alpha$ (PGC-1 $\alpha)$ and muscle carnitine palmitoyltransferase 1 (m-CPT1), reflecting increased FA transport in the muscle associated with increased oxidative metabolism. The lard $30 \%$ lipid diet led to IR without modifying the muscle lipid content. The fish-oil $30 \%$ lipid diet failed to prevent the development of hepatic steatosis and made the tissues more prone to oxidation. Overall, the present study suggests that the FA composition of muscle is more important than lipid accumulation itself in the modulation of insulin sensitivity, and indicates that precaution should be taken when advising an unphysiologically high (pharmacological) supplementation with long-chain $n$-3 PUFA.

Key words: SFA: $n$-3 PUFA: High-lipid diets: Steatosis: Insulin resistance: Oxidative stress: Mitochondria

Insulin resistance (IR) is a key component in the development of the metabolic syndrome (MetS), a very frequent condition characterised by dyslipidaemia, abdominal obesity and hypertension, which are related to an elevated risk of type 2 diabetes mellitus and $\mathrm{CVD}^{(1)}$. The incidence of MetS components, in particular obesity, IR and non-alcoholic fatty liver disease (NAFLD), is increasing rapidly in wealthy societies and has become a major public health problem, with a great impact on morbidity and mortality ${ }^{(2)}$. Liver lipid accumulation is the first stage of NAFLD and can occur as a result of the diet, de novo lipogenesis or the lipids released from adipose tissue. Then, oxidative stress, mitochondrial dysfunction and IR can lead to large hepatocyte injury, inflammation and fibrosis, which characterise the second stage of NAFLD that is called non-alcoholic steatohepatitis ${ }^{(3)}$. Fish oils that contain considerable amounts of $n$-3 fatty acid (FA) (in particular EPA and DHA) have been reported to be protective against a number of disease states and, in particular, $n-3$ FA supplementation may prevent or reduce the progression of hepatic steatosis ${ }^{(4)}$. Reduced hepatic TAG synthesis and increased $\beta$-oxidation are known to contribute to the hypolipidaemic effect of fish-oil diets. However, as tissue FA composition reflects partly dietary FA content $^{(5)}$, fish-oil diet intake may increase PUFA levels in the targeted tissues and hence render them more prone to peroxidative damage.

Abbreviations: $\beta$-HAD, $\beta$-hydroxyacyl-CoA dehydrogenase; ACC, acetyl-CoA carboxylase; FA, fatty acids; FAS, fatty acid synthase; FAT/CD36, fatty acid translocase/cluster of differentiation 36; FATP4, fatty acid transport protein 4; GSH, reduced glutathione; GSSG, oxidised glutathione; IR, insulin resistance; m-CPT1, muscle carnitine palmitoyltransferase 1; MetS, metabolic syndrome; OGTT, oral glucose tolerance test; p-ACC, phospho-acetyl-CoA carboxylase; p-Akt, phospho-Akt; PGC-1 $\alpha$, PPAR $\gamma$ co-activator $1 \alpha$; PI, peroxidisability index; NAFLD, non-alcoholic fatty liver disease; SCD1, stearoylCoA desaturase 1; SOD, superoxide dismutase; TBARS, thiobarbituric acid-reactive substances. 
Skeletal muscle is an essential tissue for whole-body energy metabolism, where FA metabolism is subject to extensive in vivo regulation, in particular the control of FA entry into the cell, the transfer of FA into the mitochondria and the capacity of the $\beta$-oxidation cycle. The balance between the uptake and utilisation of FA determines the magnitude of lipid accumulation in the muscle. Skeletal muscle is an important site for insulin action, and the accumulation of TAG and NEFA patterns in the muscle seems to affect insulin-mediated glucose uptake ${ }^{(6)}$. Insulin sensitivity is affected by the quality and quantity of dietary fat, independently of its effects on body weight. Many reports have shown that a high intake of dietary saturated fat worsens $\mathrm{IR}^{(7)}$. On the contrary, longchain $n$-3 FA may prevent IR and delay the progression of the $\mathrm{MetS}^{(8)}$, although some randomised controlled trials have failed to confirm such beneficial effects ${ }^{(9)}$.

The present study was designed to determine the impacts of three relevant nutritional lipid patterns on lipid utilisation and FA composition and their content in rat liver and muscle, two highly metabolically interrelated organs that are central to MetS pathology. These nutritional lipid patterns include the following: (1) recommended lipid diet (mixed diet); (2) consumed lipid diet in the industrialised countries (lard diet); (3) healthy lipid diet rich in long-chain n-3 PUFA (fish-oil diet). These dietary lipid patterns have been investigated at two dietary lipid levels, 5 and $30 \%$, of diet weight. Most published studies that have examined the effect of fat quality and/ or quantity in many different physiological and pathological models have been interested in individual FA or in individual oils that do not reflect any nutritional lipid profile ${ }^{(10,11)}$. Finally, we also investigated the oxidative/antioxidative stress balance in rat liver and muscle and its relationship with tissue FA content, as it is known that oxidative stress may be implicated in the progression of liver steatosis and muscle IR. The novelty of the present study is the comparison of the three diet patterns and their impacts on the phenotypes of two highly metabolically interrelated organs (liver and muscle) that are central to MetS pathology with a large number of outcomes measured, which allows an integrated overview of the physiological impact of dietary fat composition.

\section{Materials and methods}

\section{Animals and diets}

The French dietary lipid recommendation, updated in 2010, represents the core of our dietary design (http://www.anses. fr/Documents/NUT2006sa0359Ra.pdf). The French recommendation for lipids is $35-40 \%$ of energy intake $(85-95 \mathrm{~g}$ lipids/d), which is divided into $<12 \%$ SFA, $18-20 \%$ MUFA and $5-10 \%$ PUFA (with $1-2 \% n-3$ ). Although it is very difficult to replicate the human recommendations in the rat diet, we have designed the rodent diet to be broadly reflective of human dietary recommendations and patterns. The mixed diet was set up to reproduce the recommended lipid diet and composed of a blend of different lipid sources $(40 \%$ lard $+25 \%$ sunflower oil $+25 \%$ olive oil $+10 \%$ colza oil). The lard diet was set up to reproduce the currently consumed diet in many developed countries and composed of a large percentage of animal saturated lipids (90\% lard $+10 \%$ sunflower oil). Finally, the fish-oil diet was set up to reproduce a very healthy diet and composed of a high percentage of marine polyunsaturated lipids rich in longchain $n$-3 FA $(35 \%$ lard $+20 \%$ sunflower oil $+20 \%$ olive oil $+5 \%$ colza oil $+20 \%$ fish oils $(12 \%$ tuna oil $+8 \%$ sardine oil)). This mixture of tuna and sardine oils provided $3 \mathrm{~g}$ $\mathrm{EPA}+\mathrm{DHA} / \mathrm{kg}$ and about $0.70 \mathrm{~g} / \mathrm{kg}$ of other $n-3$ PUFA in the $5 \%$ lipid diets, and $18 \mathrm{~g} \mathrm{EPA}+\mathrm{DHA} / \mathrm{kg}$ and about $4.3 \mathrm{~g} / \mathrm{kg}$ of other $n$-3 PUFA in the $30 \%$ lipid diets. This mixture was made to ensure an optimal DHA:EPA ratio $(2: 1)$ in this diet that privileges the DHA level that is mostly incorporated in membrane phospholipids. The recommended amount of EPA + DHA for humans is $500 \mathrm{mg} / \mathrm{d}(0 \cdot 2 \%$ of energy intake), and it is up to $1 \mathrm{~g} / \mathrm{d}(0.4 \%$ of energy intake) for those with diagnosed MetS and CVD. However, higher doses (up to $13 \mathrm{~g} / \mathrm{d}$ ) have been investigated in several controlled trials ${ }^{(12)}$. The dose used in the present study is $3 \mathrm{~g} \mathrm{EPA}+\mathrm{DHA} / \mathrm{kg}$ diet in the $5 \%$ lipid diet $(0 \cdot 70 \%$ of energy intake) and $18 \mathrm{~g} / \mathrm{kg}$ diet in the $30 \%$ lipid diet supplemented with fish oils $(3 \cdot 15 \%$ of energy intake). An adult man consumes about $500 \mathrm{~g}$ of dry diet/d, which means that our dose of $3 \mathrm{~g} \mathrm{EPA}+\mathrm{DHA} / \mathrm{kg}$ diet ( $60 \mathrm{mg} / \mathrm{rat}$ per d) may be considered as physiological (supranutritional) and the dose $18 \mathrm{~g} / \mathrm{kg}$ diet $(360 \mathrm{mg} / \mathrm{rat}$ per d) is rather unphysiologically high (pharmacological). The detailed composition of the six experimental diets is given in Table S1 (available online)

A total of forty-eight male Wistar rats (Charles River) aged 6 weeks were housed under the conditions of constant temperature $\left(20-22^{\circ} \mathrm{C}\right)$, humidity $(45-50 \%)$ and a standard dark cycle (20.00-08.00 hours). The animals were randomised into six groups of eight and fed for 12 weeks one of the following semi-purified diets: mixed diet with 5 or $30 \%$ lipid; lard diet with 5 or $30 \%$ lipid; fish-oil diet with 5 or $30 \%$ lipid. Rats were given free access to tap water and food. Body weight and diet consumption were determined weekly. Our institution guidelines for the care and use of laboratory animals were observed, and all the experimental procedures were approved by the local ethical committee in Montpellier, France (Reference CEEA-LR-11 009).

\section{Oral glucose tolerance test}

The OGTT was performed as described previously ${ }^{(13)}$. Briefly, in week $11,16 \mathrm{~h}$ fasting rats were orally administered $2 \mathrm{~g}$ glucose/kg body weight. Blood was collected through the tail vein of conscious rats immediately before the oral administration and 10, 20, 30, 45, 60, 90, 120 and 180 min afterwards, and glucose was measured using a commercial glucometer (AccuChek Active; Roche Diagnostics). The AUC values are expressed as $\mathrm{mg}$ glucose $/ 1 \times \mathrm{min}$.

\section{Sampling and routine biochemical analysis}

Pentobarbital was used to anaesthetise $16 \mathrm{~h}$ fasted rats (Ceva Santé Animale) and blood was obtained by puncture of the 
abdominal artery. Blood was centrifuged at $1000 \boldsymbol{g}$ for $10 \mathrm{~min}$ at $4^{\circ} \mathrm{C}$, and plasma or serum was collected and stored at $-80^{\circ} \mathrm{C}$ until analysis. Liver and gastrocnemius muscle were removed, rinsed with $0.9 \% \mathrm{NaCl}$, frozen in $\mathrm{N}_{2}$ and kept at $-80^{\circ} \mathrm{C}$ until analysis. Plasma glucose, total cholesterol, HDL-cholesterol, TAG and NEFA levels were measured by enzymatic techniques (Konelab; Thermo Electron Corporation). Alanine transaminase and $\gamma$-glutamyl transferase were determined using standard methods on a Cobas MIRA automated analyser (Roche Diagnostics). Plasma insulin and leptin levels were quantified using ELISA kits (Linco Research).

\section{Histological analysis}

For microscopic studies, liver samples were fixed in 10\% neutral buffered formalin and embedded in paraffin. Serial tissue sections $(5 \mu \mathrm{m})$ were processed. Liver injury, such as steatosis, portal inflammatory infiltrate and fibrosis, was evaluated by histological examination after haematoxylin and eosin staining $^{(14)}$.

\section{$\beta$-Oxidation and oxidative stress parameters in the liver and muscle}

Liver and muscle homogenates were prepared on ice ( $1 \mathrm{~g}$ with $9 \mathrm{ml}$ phosphate buffer, $50 \mathrm{~mm}, \mathrm{pH} 7 \cdot 0$ ) using a Polytron homogeniser. Homogenate samples were saved for thiobarbituric acid-reactive substances (TBARS) and reduced glutathione (GSH)/oxidised glutathione (GSSG) measurements. The remaining homogenates were centrifuged at $1000 \mathrm{~g}$ for $10 \mathrm{~min}$ at $4^{\circ} \mathrm{C}$ and the supernatants were aliquoted and kept at $-80^{\circ} \mathrm{C}$ until analysis. Supernatant protein level was measured by Bradford's technique ${ }^{(15)}$.

$\beta$-Hydroxyacyl-CoA dehydrogenase ( $\beta$-HAD) was determined by a spectrophotometric technique according to the procedure of Yang et al. ${ }^{(16)}$. TBARS, sulphydryl groups $(-\mathrm{SH}), \mathrm{GSH}$ and GSSG levels and catalase, glutathione peroxidase, total superoxide dismutase (SOD) and Mn-SOD activities in the tissues were measured by spectrophotometric techniques as described previously ${ }^{(17)}$.

\section{Immunoblotting}

Tissue samples were homogenised using an Ultra Turax homogeniser in an ice-cold extraction buffer. Proteins were separated with 10 or $8 \%$ SDS-PAGE and then transferred onto nitrocellulose membranes. The membranes were blocked in 5\% non-fat milk for $1 \mathrm{~h}$ at room temperature. The membranes were incubated overnight with a primary antibody against acetyl-CoA carboxylase (ACC, 1:1000), phospho-ACC (p-ACC, 1:1000), Akt (1:1000), phospho-Akt (p-Akt, 1/1000), FA translocase/cluster of differentiation 36 (FAT/CD36, 1:500), muscle carnitine palmitoyltransferase 1 (m-CPT1, 1:200), FA synthase (FAS, 1:1000), fatty acid transport protein 4 (FATP4, 1:1000), PPAR $\gamma$ co-activator $1 \alpha$ (PGC-1 $\alpha, 1: 1000)$ and stearoyl-CoA desaturase 1 (SCD1, 1:200) in a blocking buffer. After washes in Tris-buffered saline/Tween, the membranes were incubated for $1 \mathrm{~h}$ with horseradish peroxidase-labelled antibodies (1:2000). After further washes, the blots were treated with enhanced chemiluminescence detection reagents. $\beta$-Actin was used as the loading reference, and blot intensities were measured using ImageJ software (NIH). The antibodies of ACC, p-ACC, Akt, p-Akt and FAS were obtained from Cell Signaling Technology, Inc.; FAT/CD36 and FATP4 from Abcam; m-CPT1 and SCD1 from Santa Cruz Biotechnology; and PGC- $1 \alpha$ from Calbiochem, Millipore SAS.

\section{Liver and muscle mRNA expression}

Real-time quantitative PCR was used to measure the mRNA expression of the target genes in the tissues and was performed as described previously ${ }^{(18)}$. The primer sequences used for real-time RT-PCR are given in Table S2 (available online). After normalisation by $18 \mathrm{~S}$ for the liver and RPS9 for the muscle, all results are expressed as a percentage of the control.

\section{Extraction and analysis of liver and muscle lipids}

Tissue samples were homogenised in $\mathrm{NaCl}(9 \mathrm{~g} / \mathrm{l})$ and Triton $\mathrm{X}-100(0 \cdot 1 \%)$, and NEFA, TAG and total cholesterol levels in the tissue homogenates were quantified by enzymatic methods (Wako-NEFA-C kit - Oxoid; Cholesterol RTU kit and TG PAP kit - Biomerieux). The lipids were then extracted from the tissue homogenates using the method of Folch et $a l .{ }^{(19)}$, and $\mathrm{P}$ was quantified in the chloroform-methanol extracts in order to determine total phospholipid quantity as described previously ${ }^{(20)}$. The chloroform-methanol lipid extract, spiked with $17: 0(2.5 \mu \mathrm{g} / \mathrm{l})$ as an FA internal standard, was used for total FA analysis by GC after trans-esterification as described previously ${ }^{(8)}$.

\section{Tissue desaturase, unsaturation and peroxidisation indices}

Because it is not possible to directly measure the activity of the enzymes that catalyse the desaturation and elongation reactions in FA metabolic pathways, results obtained in animals have supported the use of surrogate measures of desaturase activity such as the use of desaturase indices ${ }^{(21)}$. These indices are based on the ratio of the product to the precursor of individual FA. Desaturase indices were calculated as follows: $\Delta 9$, $16: 1 n-7 / 16: 0 ; \Delta 6,18: 3 n-6 / 18: 2 n-6 ; \Delta 5,20: 4 n-6 / 20: 3 n-6$. However, the $\Delta 6$ index in our muscle homogenates was estimated as $20: 3 n-6 / 18: 2 n-6$, since the proportion of $18: 3 n-6$ was too low for reliable quantification. It should be noted that this ratio also measures the elongase activity, but this step is not considered to be rate limiting, suggesting that this ratio is also a good estimate of $\Delta 6$ activity $^{(22)}$. The unsaturation index is the sum of the fraction of each FA multiplied by the number of double bonds in that $\operatorname{acid}^{(23)}$. The peroxidisability index (PI) was calculated as described previously ${ }^{(24)}$ :

$$
\begin{aligned}
\mathrm{PI}= & (\% \text { dienoic } \times 1)+(\% \text { trienoic } \times 2)+(\% \text { tetraenoic } \times 3) \\
& +(\% \text { pentaenoic } \times 4)+(\% \text { hexaenoic } \times 5) .
\end{aligned}
$$




\section{Statistical analysis}

Results are expressed as means and standard deviations. Statistical analysis was based on a two-way ANOVA followed by Fisher's multiple comparison test. When there was no significant interaction between the quantity and quality of the lipid groups, the comparison between the 5 and $30 \%$ lipid groups was done on the basis of the mean response for the three lipid quality groups combined. However, when there was a significant interaction, Fisher's post hoc test was performed among the lipid quality groups, testing the effect of the diet pattern (lipid type) within the 5 and $30 \%$ lipid groups, separately. Correlations were performed with the Spearman method. The limit of statistical significance was set at $P<0.05$. Statistical analysis was performed using the StatView program (SAS Institute).

\section{Results}

\section{Characteristics of the rats}

Body weight was statistically similar among the six experimental groups, but showing a strong trend to increase with the $30 \%$ lipid diets (Table 1). In fact, both the final body weight and weight gain were increased in the lard $30 \%$ lipid diet group compared with the mixed and the fish-oil $30 \%$ lipid diet groups (ANOVA, $P<0.05$ ). The adipose tissue weight tended to increase in the $30 \%$ lipid diet-fed rats compared with the $5 \%$ lipid diet-fed rats, and was increased in the lard $30 \%$ lipid diet-fed group ( $+35 \%)$ compared with the other groups. The dietary and energy intakes were higher in rats receiving the lard $30 \%$ lipid diet compared with those receiving the mixed or the fish-oil $30 \%$ lipid diet.

Plasma insulin level was higher in rats fed the $30 \%$ lipid diets than in those fed the $5 \%$ lipid diets (Table 1). Moreover, the AUC of the OGTT, reflecting IR, was increased with the $30 \%$ lipid diets in comparison with the $5 \%$ lipid diets, particularly with the lard 30\% lipid diet in comparison with the mixed and the fish-oil $30 \%$ lipid diets. Plasma glucose and leptin levels were increased with the lard $30 \%$ lipid diet in comparison with the mixed and the fish-oil $30 \%$ lipid diets. Blood NEFA levels were not different among the groups (Table 1), whereas plasma TAG and total cholesterol levels were decreased in rats fed the $30 \%$ lipid diets and in particular in those fed the fish-oil $30 \%$ lipid diet in comparison with those fed the mixed and the lard 30\% lipid diets. The HDL: LDL ratio was increased with the fish-oil diet in comparison with the mixed and the lard diets. Plasma alanine transaminase was not modified whatever the group, whereas $\gamma$-glutamyl transferase was increased moderately with the $30 \%$ lipid diets, reflecting slight liver injury.

\section{Liver lipid, fatty acid composition and desaturase indices}

The liver histological evaluation of hepatic steatosis showed that the rats fed the 5\% mixed and the 5\% lard-rich diets had microvacuolar steatosis with few hepatocytes displaying intracytoplasmic droplets (Fig. 1). Liver sections from the rats fed the 5\% fish oil-rich diet also showed a few steatotic

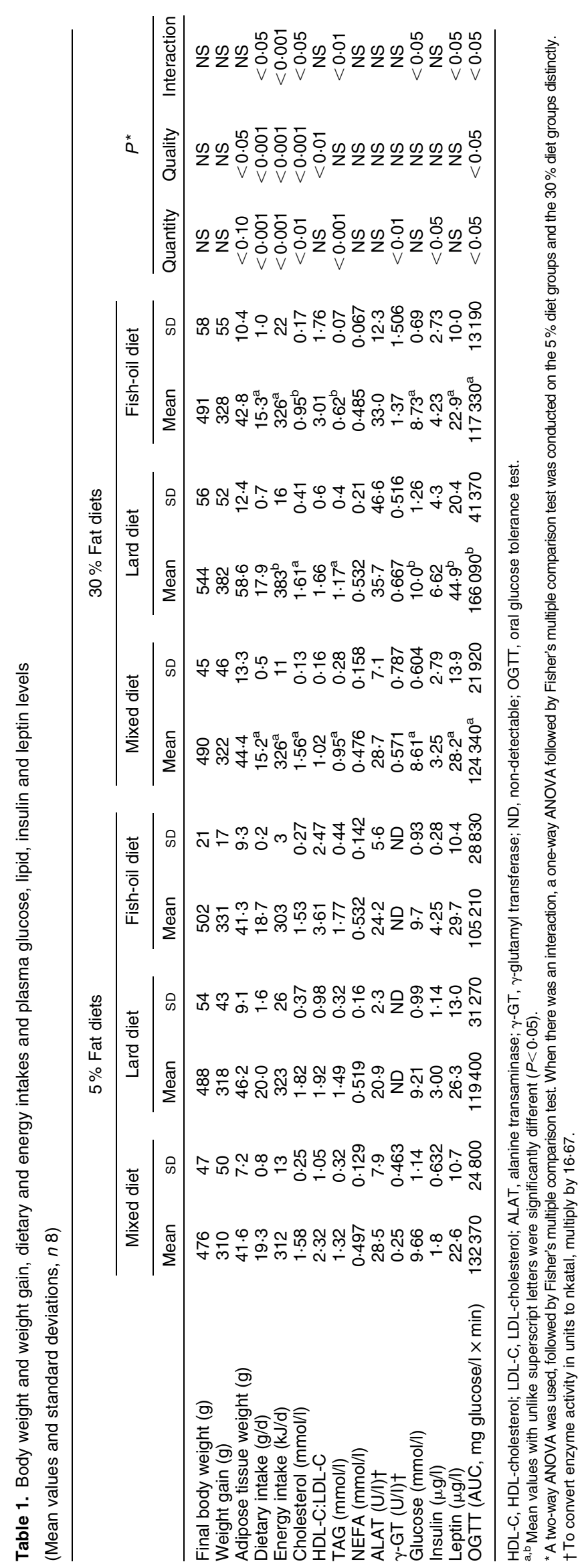


(A)

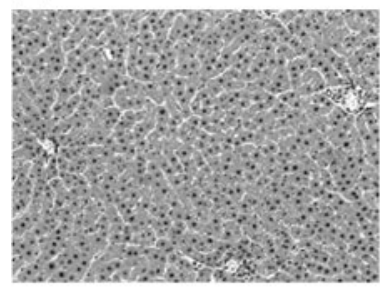

(D)

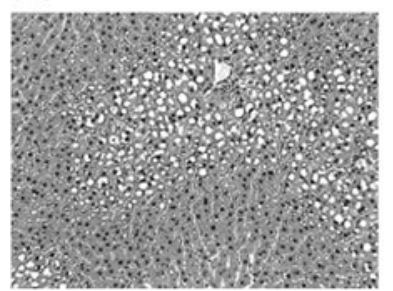

(B)

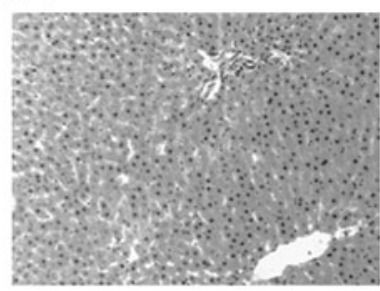

(E)

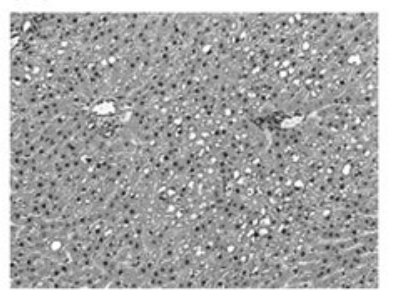

(C)

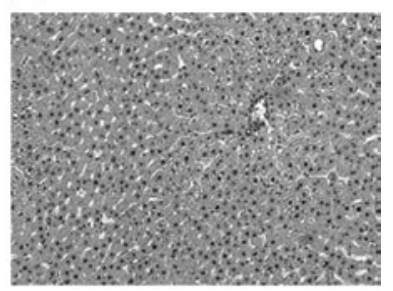

(F)

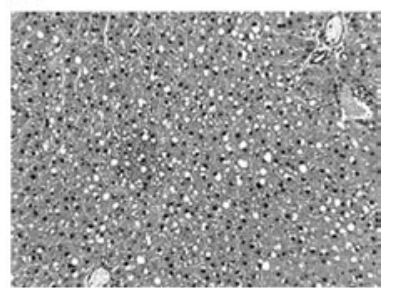

Fig. 1. Liver histology after haematoxylin/eosin staining of liver sections from representative rats of each group: (A) $5 \%$ basal diet; (B) $5 \%$ lard-rich diet; (C) $5 \%$ fish oil-rich diet; (D) $30 \%$ basal diet; (E) $30 \%$ lard-rich diet; (F) $30 \%$ fish oil-rich diet. Original magnification $100 \times$.

macrovacuoles with simple bulky fat vacuoles that distended the hepatocyte and pushed the nucleus. On the other hand, histological studies on the liver sections from the rats fed the $30 \%$ lipid diets showed high-grade macrovacuolar steatosis in the three studied groups. As expected, liver weight was increased in the $30 \%$ lipid diet-fed rats compared with the $5 \%$ lipid diet-fed rats, but lipid quality had no effect on liver weight. In addition, liver NEFA, TAG and total cholesterol levels were increased with the $30 \%$ lipid diets, reflecting overt liver steatosis. Moreover, total cholesterol level was increased with the fish-oil 30\% lipid diet in comparison with the mixed and the lard $30 \%$ lipid diets. The liver phospholipid level was not modified whatever the diet (Table 2).

The intake of the $30 \%$ lipid diets increased total liver SFA, MUFA and PUFA levels compared with that of the 5\% lipid diets (Table 3). The lard diet had no effect on the liver FA composition, although the OGTT was positively correlated with the liver SFA levels $\left(P<0.05 ; r^{2} 0 \cdot 120\right)$. In the fish-oil diet-fed rats, total $n$ - 3 PUFA quantities, and in particular DHA (22:6n-3), were higher in comparison with those fed the mixed or the lard diet (Table 3 ). The $n$-3:PUFA ratio was increased with the fish-oil diet (Table 3), and the OGTT was negatively correlated with the liver $n$-3:PUFA ratio $\left(P<0.05 ; r^{2} 0 \cdot 114\right)$.

Both $\Delta$ 9-desaturase and $\Delta 6$-desaturase indices were decreased in rats fed the $30 \%$ lipid diets compared with those fed the $5 \%$ lipid diets, whereas the $\Delta 5$-desaturase activity index was not affected by the dietary fat level (Table 3 ). With regard to the diet quality, the $\Delta 6$-desaturase and $\Delta 5$-desaturase activity indices were decreased in rats fed the fish-oil diet in comparison with those fed the mixed or the lard diet. There was no effect of dietary lipid quantity on the liver lipid unsaturation index and PI parameters. Both these indices remained comparable in rats receiving the 5 or the $30 \%$ lipid diets. However, and as expected, the quality of dietary lipids had an impact on both these indices, which were increased in rats fed the fish-oil diet in comparison with those fed the mixed or the lard diet, more in those fed the $30 \%$ lipid diets than in those fed the $5 \%$ lipid diets (Table 3 ).

\section{Liver lipogenesis pathway signalling}

The liver protein expression of FAT/CD36 and the mRNA expression of FA-binding protein 1 (FABP1) and liver carnitine palmitoyltransferase 1 ( $L$-CPT1) were decreased with the $30 \%$ lipid diets (Fig. 2). The liver protein expression of FATP 4 was not modified with the $30 \%$ lipid diets but was increased with the lard $30 \%$ lipid diet in comparison with the mixed or the fish-oil 30\% lipid diet (Fig. 2). The protein expression of PGC- $1 \alpha$ was decreased with the $30 \%$ lipid diets, while the liver mRNA expression of PPAR- $\alpha$ was not modified (Fig. 2). The liver protein expression of SCD1 (Fig. 3) was decreased with the $30 \%$ lipid diets and was increased with the lard diet in comparison with the fish-oil diet. The liver protein expression of FAS and p-ACC was decreased with the $30 \%$ lipid diets, but the total protein expression of ACC remained unchanged (Fig. 3). In addition, the mRNA expression of $M C D$ was not modified whatever the diet, whereas the mRNA expression of MCAD was decreased with the $30 \%$ lipid diets in comparison with the $5 \%$ lipid diets (Fig. 3) $\beta$-HAD activity was modified with the $30 \%$ lipid diets in comparison with the $5 \%$ lipid diets (Table 2 ). Indeed, $\beta$-HAD activity was decreased with the mixed and the fish-oil $30 \%$ lipid diets in comparison with the lard $30 \%$ lipid diet.

\section{Liver oxidative stress parameters}

Liver TBARS levels were markedly increased in rats fed the $30 \%$ lipid diets (Table 2); moreover, liver lipid oxidation was increased with the fish-oil diet in comparison with the mixed and the lard diets. Within the $5 \%$ lipid diets, the liver TBARS level was increased by $22 \%$ with the fish-oil diet compared with the mixed diet, whereas within the $30 \%$ lipid diets, the liver TBARS level was increased by $104 \%$ with the fish-oil 
Table 2. Liver lipids and oxidative stress parameters

(Mean values and standard deviations, $n 8$ )

\begin{tabular}{|c|c|c|c|c|c|c|c|c|c|c|c|c|c|c|c|}
\hline & \multicolumn{6}{|c|}{$5 \%$ Fat diets } & \multicolumn{6}{|c|}{$30 \%$ Fat diets } & & & \\
\hline & \multicolumn{2}{|c|}{ Mixed diet } & \multicolumn{2}{|c|}{ Lard diet } & \multicolumn{2}{|c|}{ Fish-oil diet } & \multicolumn{2}{|c|}{ Mixed diet } & \multicolumn{2}{|c|}{ Lard diet } & \multicolumn{2}{|c|}{ Fish-oil diet } & \multicolumn{3}{|c|}{$P^{*}$} \\
\hline & Mean & SD & Mean & SD & Mean & SD & Mean & SD & Mean & SD & Mean & SD & Quantity & Quality & Interaction \\
\hline Liver weight (g) & 10.5 & 1.4 & $10 \cdot 6$ & 1.1 & $11 \cdot 2$ & 0.9 & 11.0 & 1.6 & $12 \cdot 0$ & $2 \cdot 0$ & $12 \cdot 2$ & $2 \cdot 0$ & $<0.05$ & NS & NS \\
\hline NEFA ( $\mu \mathrm{mol} / \mathrm{g}$ wet weight) & 9.58 & $1 \cdot 15$ & 8.84 & 1.07 & 9.22 & $2 \cdot 39$ & $19 \cdot 0$ & $8 \cdot 1$ & $19 \cdot 0$ & $8 \cdot 15$ & 21.6 & $10 \cdot 9$ & $<0.001$ & NS & NS \\
\hline Cholesterol ( $\mu \mathrm{mol} / \mathrm{g}$ wet weight) & 5.65 & 1.55 & 5.48 & 1.6 & 7.35 & 1.70 & $11 \cdot 0^{\mathrm{a}}$ & $2 \cdot 2$ & $9 \cdot 16^{\mathrm{a}}$ & 1.49 & $15 \cdot 6^{\mathrm{b}}$ & $3 \cdot 2$ & $<0.001$ & $<0.001$ & $<0.05$ \\
\hline Phospholipids ( $\mu \mathrm{mol} / \mathrm{g}$ wet weight) & $42 \cdot 2$ & 3.7 & 43.9 & 1.6 & $44 \cdot 3$ & $2 \cdot 6$ & $43 \cdot 2$ & $2 \cdot 8$ & $44 \cdot 4$ & 4.5 & $45 \cdot 9$ & 3.2 & NS & NS & NS \\
\hline TAG ( $\mu \mathrm{mol} / \mathrm{g}$ wet weight) & 28.5 & 4.7 & $25 \cdot 0$ & 5.9 & 35.7 & 9.1 & 59.6 & $19 \cdot 1$ & $62 \cdot 0$ & $17 \cdot 9$ & $64 \cdot 1$ & $21 \cdot 8$ & $<0.001$ & NS & NS \\
\hline$\beta-\mathrm{HAD}$ (nkatal/mg protein) & $12 \cdot 18$ & 1.35 & 11.62 & 1.27 & 11.38 & 1.85 & $6 \cdot 73^{\mathrm{a}}$ & 1.72 & $13 \cdot 13^{b}$ & 1.73 & $6 \cdot 42^{\mathrm{a}}$ & $1 \cdot 20$ & $<0.0001$ & $<0.0001$ & $<0.0001$ \\
\hline TBARS (nmol/g wet weight) & $62 \cdot 4^{\mathrm{a}}$ & $10 \cdot 8$ & $59 \cdot 0^{\mathrm{a}}$ & $7 \cdot 8$ & $76 \cdot 1^{\mathrm{b}}$ & 14.6 & $72 \cdot 8^{\mathrm{a}}$ & $10 \cdot 1$ & $97 \cdot 5^{\mathrm{b}}$ & $21 \cdot 7$ & $149^{c}$ & 16 & $<0.001$ & $<0.001$ & $<0.001$ \\
\hline -SH groups (nmol/mg protein) & $45 \cdot 1$ & $9 \cdot 1$ & $49 \cdot 2$ & $12 \cdot 3$ & $45 \cdot 3$ & $12 \cdot 1$ & 19.5 & $8 \cdot 16$ & 17.5 & 9.99 & $12 \cdot 0$ & 9.34 & $<0.001$ & NS & NS \\
\hline GSH (nmol/g wet weight) & 4029 & 589 & 4191 & 486 & 4145 & 743 & 3271 & 473 & 2932 & 478 & 3273 & 230 & $<0.001$ & NS & NS \\
\hline GSSG (nmol/g wet weight) & $52 \cdot 3$ & 9.3 & $45 \cdot 9$ & $5 \cdot 8$ & 49.9 & 4.5 & 43.9 & 11.9 & 38.4 & 9.4 & $36 \cdot 3$ & 8.7 & $<0.001$ & NS & NS \\
\hline GSH:GSSG & 78.8 & $16 \cdot 4$ & $91 \cdot 7$ & 9.3 & $82 \cdot 8$ & $11 \cdot 2$ & $78 \cdot 2$ & $18 \cdot 8$ & 79.1 & $9 \cdot 1$ & $92 \cdot 1$ & 13.9 & NS & NS & NS \\
\hline Catalase $(\mathrm{U} / \mathrm{mg}$ protein $) \dagger$ & $1138^{a, b}$ & 251 & $1025^{\mathrm{a}}$ & 123 & $1261^{\mathrm{b}}$ & 199 & 1150 & 202 & 1113 & $15 \cdot 0$ & 1015 & 139 & NS & NS & $<0.05$ \\
\hline SOD (U/mg protein)† & $23 \cdot 2$ & 4.6 & $22 \cdot 0$ & $2 \cdot 3$ & $25 \cdot 3$ & 4.7 & 23.4 & $5 \cdot 7$ & $22 \cdot 1$ & 3.8 & $20 \cdot 3$ & 3.0 & NS & NS & NS \\
\hline Mn-SOD (U/mg protein)† & $2 \cdot 13$ & 0.69 & 1.91 & 0.40 & 2.09 & 0.39 & 1.87 & 0.57 & $2 \cdot 16$ & 0.50 & 1.98 & 0.46 & NS & NS & NS \\
\hline GPx (U/mg protein) $\dagger$ & 7.77 & 1.74 & 6.72 & 1.06 & $8 \cdot 30$ & 1.87 & $7 \cdot 34^{a, b}$ & 1.31 & $7.49^{\mathrm{a}}$ & 1.45 & $6 \cdot 16^{\mathrm{b}}$ & 0.94 & NS & NS & $<0.05$ \\
\hline
\end{tabular}

$\beta$-HAD, $\beta$-hydroxyacyl-CoA dehydrogenase; TBARS, thiobarbituric acid-reactive substances; GSH, reduced glutathione; GSSG, oxidised glutathione; SOD, superoxide dismutase; GPx, glutathione peroxidase.

*A two-way ANOVA was used, followed by Fisher's multiple comparisons test. When there was an interaction, a one-way ANOVA followed by Fisher's multiple comparison test was conducted on the $5 \%$ diet groups and the

†To convert enzyme activity in units to nkatal, multiply by 16.67 . 
Table 3. Total fatty acid (FA) composition of the liver homogenates (mg FA/g tissue)*

(Mean values and standard deviations, $n 8$ )

\begin{tabular}{|c|c|c|c|c|c|c|c|c|c|c|c|c|c|c|c|}
\hline & \multicolumn{6}{|c|}{$5 \%$ Fat diets } & \multicolumn{6}{|c|}{$30 \%$ Fat diets } & & & \\
\hline & \multicolumn{2}{|c|}{ Mixed diet } & \multicolumn{2}{|c|}{ Lard diet } & \multicolumn{2}{|c|}{ Fish-oil diet } & \multicolumn{2}{|c|}{ Mixed diet } & \multicolumn{2}{|c|}{ Lard diet } & \multicolumn{2}{|c|}{ Fish-oil diet } & \multicolumn{3}{|c|}{$P+$} \\
\hline & Mean & SD & Mean & SD & Mean & SD & Mean & SD & Mean & SD & Mean & SD & Quantity & Quality & Interaction \\
\hline Total lipids & 55.4 & 7.4 & $45 \cdot 3$ & 6.9 & 57.6 & 14.4 & $82 \cdot 8$ & $34 \cdot 1$ & 87.8 & 13.7 & 90.0 & $32 \cdot 8$ & $<0.001$ & NS & NS \\
\hline SFA & 20.5 & 3.7 & $16 \cdot 3$ & $2 \cdot 2$ & 21.5 & 3.8 & $26 \cdot 6$ & 11.8 & 32.5 & $7 \cdot 2$ & $27 \cdot 4$ & 8.3 & $<0.001$ & NS & NS \\
\hline $14: 0$ & 0.606 & 0260 & 0.387 & 0.092 & 0.661 & 0.213 & 0.649 & 0.423 & 0.801 & 0.494 & 0.512 & 0.218 & NS & NS & NS \\
\hline $16: 0$ & $12 \cdot 9$ & 1.6 & 10.5 & 1.3 & $14 \cdot 8$ & $3 \cdot 2$ & $16 \cdot 7$ & $7 \cdot 7$ & $22 \cdot 2$ & 4.8 & $18 \cdot 4$ & 6.5 & $<0.001$ & NS & $<0.05$ \\
\hline $18: 0$ & 7.06 & 2.23 & $5 \cdot 27$ & 0.68 & 6.07 & 1.66 & 8.72 & 4.09 & 9.51 & $2 \cdot 84$ & 8.44 & 1.87 & $<0.001$ & NS & NS \\
\hline MUFA & $16 \cdot 6$ & 3.9 & 14.9 & $2 \cdot 7$ & $17 \cdot 7$ & 7.5 & 24.2 & $12 \cdot 1$ & $27 \cdot 0$ & $4 \cdot 8$ & $25 \cdot 6$ & $11 \cdot 3$ & $<0.001$ & NS & NS \\
\hline $16: 1 n-9$ & 0.214 & 0.053 & 0.198 & 0.038 & 0.267 & 0.097 & 0.552 & 0.352 & 0.330 & 0.088 & 0.540 & 0.349 & $<0.001$ & NS & NS \\
\hline $16: 1 n-7$ & 2.55 & 0.79 & $2 \cdot 69$ & 0.62 & 3.95 & $2 \cdot 16$ & 0.532 & 0.239 & 0.975 & 0.338 & 0.876 & 0.423 & $<0.001$ & NS & NS \\
\hline $18: 1 n-9$ & 11.6 & $2 \cdot 6$ & $9 \cdot 87$ & 2.06 & 9.08 & 2.56 & 21.9 & 11.0 & $23 \cdot 6$ & 4.0 & $22 \cdot 9$ & $10 \cdot 2$ & $<0.001$ & NS & NS \\
\hline $18: 1 n-7$ & $2 \cdot 17$ & 0.58 & $2 \cdot 13$ & 0.51 & 4.33 & 6.95 & 1.03 & 0.42 & 1.80 & 0.42 & 1.14 & 0.36 & NS & NS & NS \\
\hline PUFA & $18 \cdot 3$ & 3.6 & 14.0 & 2.5 & 18.4 & $4 \cdot 3$ & 32.0 & $12 \cdot 6$ & $28 \cdot 3$ & 5.5 & 37.0 & 13.7 & $<0.001$ & NS & NS \\
\hline $18: 2 n-6$ & 6.48 & $2 \cdot 32$ & 4.55 & 1.06 & 6.63 & 1.92 & $17 \cdot 6$ & $7 \cdot 6$ & $15 \cdot 4$ & $2 \cdot 7$ & $15 \cdot 9$ & $6 \cdot 0$ & $<0.001$ & NS & NS \\
\hline $18: 3 n-6$ & 0.172 & 0.041 & 0.143 & 0.051 & 0.040 & 0.038 & 0.314 & 0.171 & 0.236 & 0.042 & 0.121 & 0.063 & $<0.001$ & $<0.001$ & NS \\
\hline $20: 3 n-9$ & $0 \cdot 166^{a}$ & 0.125 & $0.241^{b, a}$ & 0.077 & $0.086^{a}$ & 0.078 & $N D^{\mathrm{a}}$ & ND & $0.222^{b}$ & 0.035 & $N D^{a}$ & ND & $<0.001$ & $<0.001$ & $<0.05$ \\
\hline $20: 3 n-6$ & 0.459 & 0.146 & 0.372 & 0.134 & 0.408 & 0.106 & 0.512 & 0.371 & 0.415 & 0.133 & 0.451 & 0.146 & NS & NS & NS \\
\hline $20: 4 n-6$ & $6 \cdot 76$ & 1.74 & $6 \cdot 31$ & 0.93 & 3.66 & 0.63 & $7 \cdot 70$ & $2 \cdot 64$ & $7 \cdot 76$ & 1.82 & 4.87 & 0.80 & $<0.05$ & $<0.001$ & NS \\
\hline $20: 5 n-3$ & 0.124 & 0.077 & 0.081 & 0.046 & 1.88 & 0.57 & 0.142 & 0.103 & 0.137 & 0.048 & 2.78 & 1.25 & NS & $<0.001$ & NS \\
\hline $22: 5 n-3$ & $0.176^{a}$ & 0.084 & $0.143^{a}$ & 0.040 & $0.691^{\mathrm{b}}$ & 0.343 & $0.461^{a}$ & 0.240 & $0.511^{\mathrm{a}}$ & 0.131 & $1.97^{\mathrm{b}}$ & 1.05 & $<0.001$ & $<0.001$ & $<0.01$ \\
\hline $22: 6 n-3$ & $2 \cdot 17^{\mathrm{a}}$ & 0.84 & $1.58^{\mathrm{a}}$ & 0.53 & $3.72^{\mathrm{b}}$ & 1.20 & $2 \cdot 29^{\mathrm{a}}$ & 1.44 & $1.76^{\mathrm{a}}$ & 0.42 & $10 \cdot 1^{\mathrm{b}}$ & 4.6 & $<0.001$ & $<0.001$ & $<0.001$ \\
\hline$n-6$ PUFA & $15 \cdot 1$ & 3.3 & $11 \cdot 8$ & 1.9 & 11.6 & $2 \cdot 4$ & 28.0 & $11 \cdot 1$ & 24.8 & 4.4 & $21 \cdot 7$ & 6.9 & $<0.001$ & NS & NS \\
\hline$n-3$ PUFA & $3.00^{\mathrm{a}}$ & 0.97 & $2.00^{\mathrm{a}}$ & 0.56 & $6 \cdot 71^{\mathrm{b}}$ & $2 \cdot 18$ & $4.01^{\mathrm{a}}$ & $2 \cdot 1$ & $3 \cdot 22^{a}$ & $1 \cdot 24$ & $15 \cdot 3^{\mathrm{b}}$ & $7 \cdot 0$ & $<0.001$ & $<0.0001$ & $<0.01$ \\
\hline$\Delta 9$-Desaturase index & 0.198 & 0.053 & 0.261 & 0.067 & 0.254 & 0.080 & 0.032 & 0.006 & 0.045 & 0.014 & 0.046 & 0.010 & $<0.0001$ & NS & NS \\
\hline$\Delta 6$-Desaturase index§ & $0.029^{\mathrm{a}}$ & 0.010 & $0.031^{\mathrm{a}}$ & 0.007 & $0.011^{\mathrm{b}}$ & 0.004 & $0.017^{\mathrm{a}}$ & 0.004 & $0.015^{\mathrm{a}}$ & 0.003 & $0.008^{\mathrm{b}}$ & 0.001 & $<0.0001$ & $<0.0001$ & $<0.05$ \\
\hline$\Delta 5$-Desaturase index $\|$ & $15 \cdot 5$ & $4 \cdot 2$ & $18 \cdot 6$ & $6 \cdot 0$ & 9.4 & 2.5 & $19 \cdot 2$ & $10 \cdot 3$ & $19 \cdot 0$ & $9 \cdot 8$ & 11.6 & 3.7 & NS & $<0.01$ & NS \\
\hline $\mathrm{UI}$ & 140 & 17 & 140 & 4 & 148 & 14 & $143^{\mathrm{a}}$ & 17 & $127^{\mathrm{b}}$ & 15 & $181^{\mathrm{C}}$ & 9 & NS & $<0.001$ & $<0.001$ \\
\hline $\mathrm{PI}$ & $77 \cdot 6^{a, b}$ & 14.0 & $76 \cdot 3^{\mathrm{a}}$ & 3.8 & $85 \cdot 8^{\mathrm{b}}$ & 9.9 & $75 \cdot 5^{\mathrm{a}}$ & $16 \cdot 7$ & $61 \cdot 1^{\mathrm{b}}$ & $13 \cdot 1$ & $112 \cdot 7^{c}$ & 4.6 & NS & $<0.001$ & $<0.001$ \\
\hline
\end{tabular}

$\mathrm{ND}$, non-detectable; $\mathrm{UI}$, unsaturation index; $\mathrm{PI}$, peroxidation index.

a,b,c Mean values with unlike superscript letters were significantly different $(P<0.05)$

"The results of the major FA $(>0.1 \%$ ) are expressed as $\mathrm{mg} \mathrm{FA} / \mathrm{g}$ liver.
†A two-way ANOVA was used, followed by Fisher's multiple comparison test. When there was an interaction, a one-way ANOVA followed by Fisher's multiple comparison test was conducted on the $5 \%$ diet groups and the $30 \%$ diet groups distinctly.

$\ddagger \Delta 9$-Desaturase index $=16: 1 n-7 / 16: 0$.

$\S \Delta 6$-Desaturase index $=18: 3 n-6 / 18: 2 n-6$

$\| \Delta 5$-Desaturase index $=20: 4 n-6 / 20: 3 n-6$. 

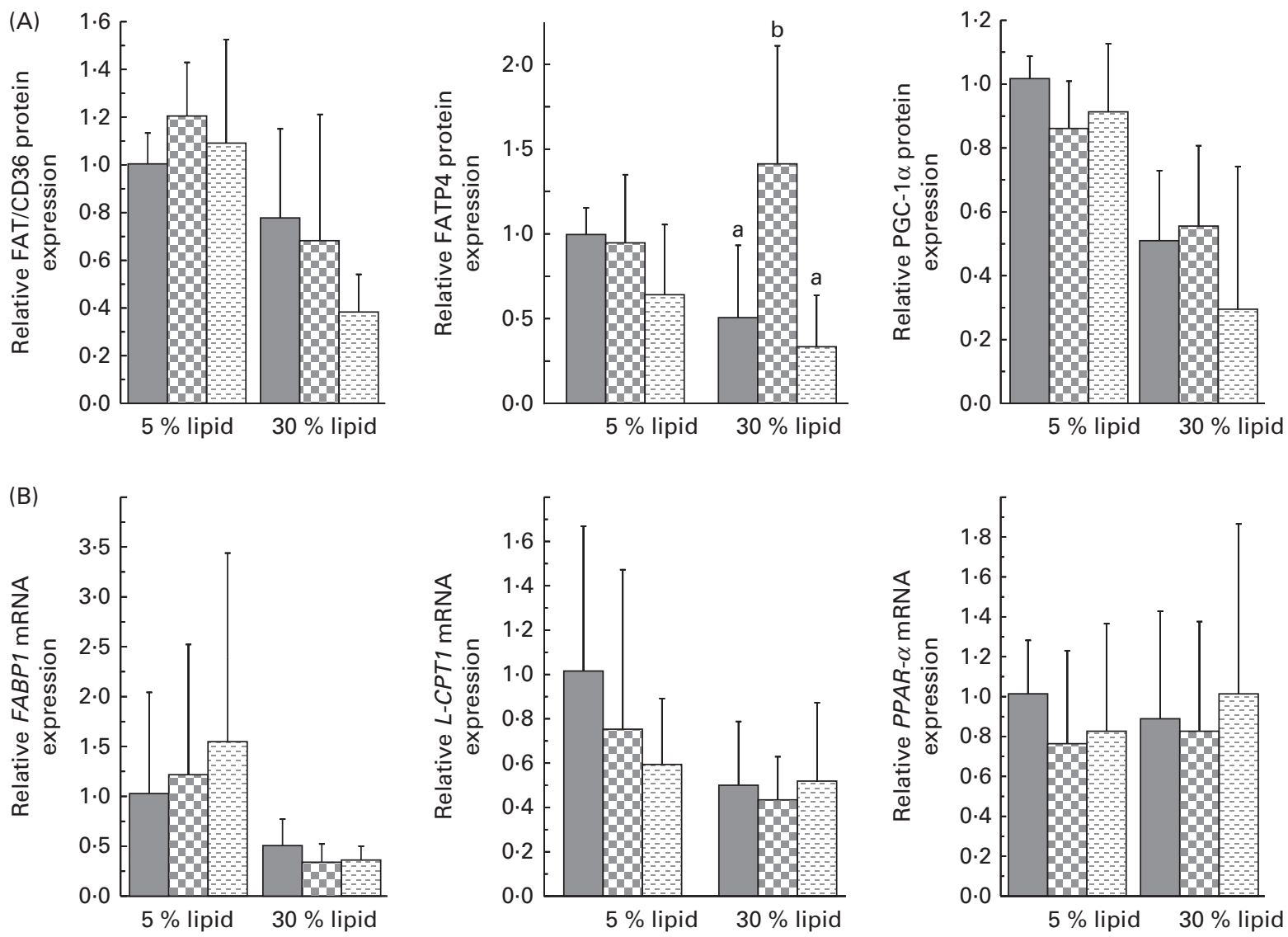

Fig. 2. Liver protein expression of fatty acid translocase/cluster of differentiation 36 (FAT/CD36), fatty acid transport protein 4 (FATP4) and PPAR $\gamma$ co-activator $1 \alpha(P G C-1 \alpha)$, and liver gene expression of fatty acid-binding protein 1 (FABP1), liver carnitine palmitoyltransferase 1 (L-CPT1) and PPAR- $\alpha$. (A) Western blot was performed on protein extracts from the liver of rats, using anti-FAT/CD36, anti-FATP4 and anti-PGC- $1 \alpha$ antibodies. Anti- $\beta$-actin antibody was used to confirm equal loading. Western blot was quantified using ImageJ software $(\mathrm{NIH})$. (B) Quantitative real-time PCR analysis of the mRNA expression of FABP, L-CPT1 and $P P A R-\alpha$ in the liver. Values are means $(n 6-8)$, with standard deviations represented by vertical bars. (A) There was a significant effect of lipid quantity on FAT/CD36 and PGC-1 $\alpha$ protein expression $(P<0.001)$. There was a significant effect of lipid quantity on FATP4 protein expression $(P<0.01)$ with a significant interaction between the quantity and quality of lipid $(P<0.05)$. (B) There was a significant effect of lipid quantity on FABP1 and L-CPT1 gene expression $(P<0.05)$. $\square$, Basal diet; 圆, lard-rich diet; $⿴ 囗 十$, fish oil-rich diet.

diet compared with the mixed diet. TBARS levels were positively correlated with the liver $n$-3:PUFA ratio $(P<0 \cdot 001$; $\left.r^{2} 0.319\right)$ and the PI $\left(P<0.001 ; r^{2} 0.377\right)$. Protein oxidation was increased with the $30 \%$ lipid diets as $-\mathrm{SH}$ levels were decreased, while the quality of dietary FA in the diet had no effect (Table 2). GSH and GSSG levels were decreased with the $30 \%$ lipid diets, while GSH:GSSG remained unchanged. Liver catalase, SOD, Mn-SOD and glutathione peroxidase activities were not modified with the $30 \%$ lipid diets in comparison with the $5 \%$ lipid diets (Table 2). However, glutathione peroxidase activity was decreased with the fish-oil $30 \%$ lipid diet in comparison with the lard 30\% lipid diet, and catalase activity was increased with the fish-oil $5 \%$ lipid diet in comparison with the lard 5\% lipid diet.

\section{Muscle lipid fatty acid composition and desaturase activity}

Muscle NEFA, TAG and phospholipid levels were not modified whatever the diet (Table 4). Total cholesterol level was not modified with the $30 \%$ lipid diets but was increased with the lard 5\% lipid diet in comparison with the mixed and the fish-oil 5\% lipid diets. Total SFA and MUFA were not modified with the $30 \%$ lipid diets, while total PUFA were higher in the muscle of rats fed the $30 \%$ lipid diets than in those fed the $5 \%$ lipid diets (Table 5). In rats fed the lard diet, total SFA, and in particular 18:0, was increased and the OGTT was positively correlated with the muscle 18:0 levels $\left(P<0 \cdot 05 ; r^{2} 0 \cdot 130\right)$. In rats fed the fish-oil diet, total $n-3$ PUFA quantities (DHA) were higher in comparison with those fed the mixed and the lard diets. The $n-6: n-3$ ratio was decreased and the $n$ 3:PUFA ratio was increased with the fish-oil diet (Table 5), and the OGTT was negatively correlated with the muscle $n$-3:PUFA ratio $\left(P<0.05 ; r^{2} 0.084\right)$.

As shown in Table 5, the muscle 16:1n-7/16:0 ratio, the $\Delta 9$-desaturase activity index, was dramatically decreased in rats fed the $30 \%$ lipid diets compared with those fed the $5 \%$ lipid diets. The $\Delta 6$-desaturase activity index, measured as the $20: 3 n-6 / 18: 2 n-6$ ratio because the muscle $18: 3 n-6$ was not measurable, was decreased in rats fed the $30 \%$ lipid diets compared with those fed the $5 \%$ lipid diets. The $\Delta 5$-desaturase activity index, $20: 4 n-6 / 20: 3 n-6$ ratio, was increased in rats 

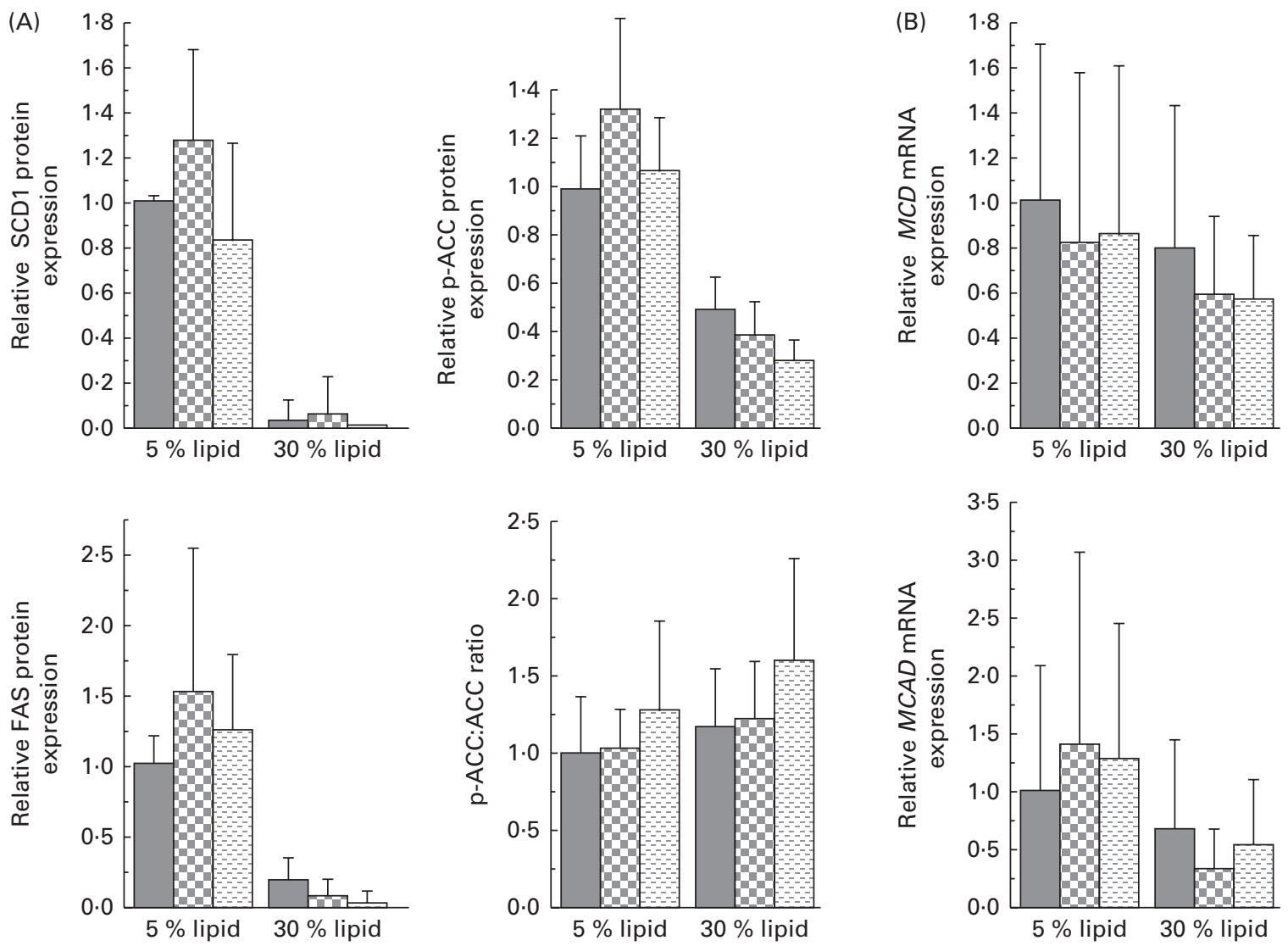

Fig. 3. Liver protein expression of stearoyl-CoA desaturase 1 (SCD1), fatty acid synthase (FAS) and phospho-acetyl-CoA carboxylase (p-ACC) and p-ACC:ACC ratio, and liver gene expression of malonyl CoA decarboxylase $(M C D)$ and medium-chain acyl-CoA dehydrogenase $(M C A D)$. (A) Western blot was performed on protein extracts from the liver of rats, using anti-SCD1, anti-FAS, anti-ACC and anti-p-ACC antibodies. Anti- $\beta$-actin antibody was used to confirm equal loading Western blot was quantified using ImageJ software $(\mathrm{NIH})$. (B) Quantitative real-time PCR analysis of the mRNA expression of $M C D$ and $M C A D$ in the liver. Values are means $(n 6-8)$, with standard deviations represented by vertical bars. (A) There was a significant effect of lipid quantity and quality on SCD1 protein expression $(P<0.001, P<0.05$, respectively). There was a significant effect of lipid quantity on $\mathrm{p}$-ACC and FAS protein expression $(P<0.001)$. (B) There was a

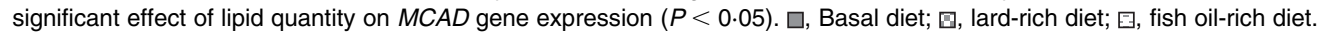

fed the $30 \%$ lipid diets compared with those fed the $5 \%$ lipid diets, and was decreased in rats fed the fish-oil diet in comparison with those fed the mixed and the lard diets. Finally, the muscle unsaturation index and PI were not modified with the $30 \%$ lipid diets in comparison with the $5 \%$ lipid diets, while these indices were increased in rats fed the fish-oil diet in comparison with those fed the mixed and the lard diets.

\section{Muscle lipogenesis pathway signalling and phospho-Akt/Akt protein expression}

The muscle protein expressions of FAT/CD36 and m-CPT1 (Fig. 4) were increased, respectively, significantly and almost significantly $(P=0.0506)$, with the $30 \%$ lipid diets. The muscle protein expression of FATP 4 and the mRNA expression of $F A B P 3$ were not modified whatever the diet (data not shown). The muscle protein expression of SCD1 (Fig. 4), FAS and p-ACC (data not shown) was not modified whatever the diet. However, the protein expression of SCD1 tended to decrease with the fish-oil diet (Fig.4; $P=0.0588$ ). Moreover, the mRNA expression of $M C D$ was not modified whatever the diet (data not shown). The muscle mRNA expression of
$M C A D$ (data not shown) and muscle $\beta$-HAD activity (Table 4) were not modified whatever the diet. The muscle protein expression of PGC- $1 \alpha$ was almost significantly increased with the $30 \%$ lipid diets (Fig. $4 ; P=0.053$ ), while the mRNA expression of $P P A R-\alpha$ was not modified (data not shown). The muscle protein p-Akt:Akt ratio was not modified whatever the diet (data not shown), although the p-Akt:Akt ratio was negatively correlated with the OGTT $\left(P<0 \cdot 05, r^{2} 0 \cdot 193\right)$.

\section{Muscle oxidative stress parameters}

As shown in Table 4, 30\% lipid intake had no impact on muscle lipid oxidation (TBARS levels) or protein oxidation (-SH group levels). However, the muscle TBARS level was increased with the fish-oil diet and positively correlated with the muscle $n$-3:PUFA ratio $\left(P<0.05 ; r^{2} 0.124\right)$ and the PI $\left(P<0.05 ; r^{2} 0.087\right)$. The muscle GSH level was decreased with the $30 \%$ lipid diets, whereas the GSSG level was not detectable in the muscle by our spectrophotometric method. Muscle antioxidant enzyme activities (SOD, Mn-SOD and glutathione peroxidase) remained unchanged, but catalase activity was increased with the $30 \%$ lipid diets in comparison 
with the $5 \%$ lipid diets (Table 4), and was increased with the fish-oil 30\% lipid diet in comparison with the mixed and the lard 30\% lipid diets.

\section{Discussion}

The present study was designed to determine the impacts of different relevant patterns of dietary lipids (quantity and quality) on lipid utilisation and FA content in rat liver and muscle tissues and their consequences on NAFLD and IR. The present results show that the intake of $30 \%$ lipid diets increased liver FA and TAG contents and led to liver steatosis (liver lipid droplets). The lard diet had no effect on liver FA composition, probably because of the high dietary level of MUFA or the in vivo synthesis of MUFA from SFA. In accordance with this observation, the protein expression of SCD1, a $\Delta 9$-desaturase that catalyses the synthesis of monounsaturated long-chain FA from saturated fatty acyl-CoA, was increased with the lard diet. In contrast, the fish-oil diet considerably modulated the liver FA composition, where $n-3$ PUFA level was increased in the liver of rats fed the fish-oil diet. Moreover, the fish-oil diet decreased the liver $\Delta 6$-desaturase and $\Delta 5$-desaturase activity indices, which is in line with the recent reports ${ }^{(25)}$.

Liver FA can be derived from the diet and are synthesised de novo in case of excess carbohydrates, and then they are oxidised or esterified to glycerol for the synthesis of TAG ${ }^{(26)}$. In the present study, the protein expression of the major actors of lipid metabolism (FAT/CD36, FABP1, ACC and FAS) was decreased and the protein expression of SCD1 was almost suppressed in rats fed the $30 \%$ lipid diets. Moreover, the p-ACC:ACC ratio and the gene expression of $M C D$ were unchanged. Surprisingly, the protein expression of FATP4 was increased in rats fed the lard 30\% lipid diet. As the content of palmitic acid is higher in the lard diet than in the mixed and the fish-oil diets, it is possible that the protein expression of FATP4 was increased because FATP4 was more effective than the other FA transporters in palmitate transport, as suggested previously ${ }^{(27)}$. It has been well documented that hepatic lipogenesis is markedly reduced with high-lipid diets, with the transcription of hepatic genes encoding FAS, SCD1 and ACC being rapidly suppressed, and that this effect is more pronounced with $n-3 \mathrm{FA}^{(28)}$. Moreover, it has been reported that $n-3$ supplementation may prevent or reduce hepatic steatosis ${ }^{(4)}$. However, in the present study, we did not observe any reduced lipogenesis or lower liver lipid content with the fish-oil diet compared with the other two studied diets.

Mitochondrial biogenesis is largely controlled by the transcriptional co-activator PGC-1 $\alpha$. This later induces the genes involved in mitochondrial $\beta$-oxidation, such as $M C A D$ and $L-C P T 1^{(29,30)}$. In the present study, the protein expression of PGC- $1 \alpha$ was decreased with the $30 \%$ lipid diets, without any effect of the dietary lipid quality. In accordance with this, the gene expression of $L-C P T 1$, which allows FA to cross the mitochondrial membrane ${ }^{(31)}$, and the gene expression of $M C A D$, the first enzyme in the $\beta$-oxidation cycle, were down-regulated with the $30 \%$ lipid diets. Moreover, $\beta$-HAD activity, the third enzyme in the $\beta$-oxidation cycle, was 
Table 5. Total fatty acid (FA) composition of the muscle homogenates (mg FA/g tissue)* (Mean values and standard deviations, $n$ )

\begin{tabular}{|c|c|c|c|c|c|c|c|c|c|c|c|c|c|c|c|}
\hline & \multicolumn{6}{|c|}{$5 \%$ Fat diets } & \multicolumn{6}{|c|}{$30 \%$ Fat diets } & & & \\
\hline & \multicolumn{2}{|c|}{ Mixed diet } & \multicolumn{2}{|c|}{ Lard diet } & \multicolumn{2}{|c|}{ Fish-oil diet } & \multicolumn{2}{|c|}{ Mixed diet } & \multicolumn{2}{|c|}{ Lard diet } & \multicolumn{2}{|c|}{ Fish-oil diet } & \multicolumn{3}{|c|}{$P+$} \\
\hline & Mean & SD & Mean & SD & Mean & SD & Mean & SD & Mean & SD & Mean & SD & Quantity & Quality & Interaction \\
\hline Total lipids & 28.9 & 9.4 & $31 \cdot 1$ & 12.5 & $22 \cdot 1$ & 4.9 & 28.5 & $6 \cdot 9$ & 29.2 & $12 \cdot 2$ & 24.0 & $4 \cdot 8$ & NS & NS & NS \\
\hline SFA & 11.5 & 2.9 & 12.9 & 5.4 & 8.88 & 1.87 & 9.56 & $2 \cdot 05$ & $12 \cdot 8$ & 4.9 & $9 \cdot 18$ & 1.95 & NS & $<0.05$ & NS \\
\hline $14: 0$ & 0.601 & 0.253 & 0.73 & 0.505 & 0.374 & 0.148 & 0.286 & 0.063 & 0.516 & 0.304 & 0.316 & 0.155 & $<0.01$ & $<0.01$ & NS \\
\hline $16: 0$ & 7.63 & 2.05 & 8.9 & 3.82 & $6 \cdot 1$ & 1.38 & $5 \cdot 86$ & 1.25 & 7.89 & 3.17 & $12 \cdot 6$ & $13 \cdot 6$ & NS & NS & NS \\
\hline $18: 0$ & 2.88 & 0.83 & 3.06 & 0.89 & $2 \cdot 32$ & 0.44 & 3.37 & 0.89 & $4 \cdot 18$ & 1.43 & 3.11 & 0.73 & $<0.01$ & $<0.01$ & NS \\
\hline MUFA & 9.52 & 4.43 & $10 \cdot 4$ & $6 \cdot 4$ & 6.06 & $2 \cdot 39$ & 8.62 & $2 \cdot 71$ & $8 \cdot 15$ & 5.05 & 5.85 & 1.93 & NS & NS & NS \\
\hline $16: 1 n-9$ & 0.145 & 0.043 & 0.146 & 0.102 & 0.13 & 0.056 & 0.138 & 0.059 & 0.128 & 0.076 & 0.231 & 0.3 & NS & NS & NS \\
\hline $16: 1 n-7$ & 1.83 & 1.04 & $2 \cdot 33$ & 2.06 & 1.27 & 0.61 & 0.364 & 0.114 & 0.589 & 0.394 & 1.38 & $2 \cdot 26$ & $<0.05$ & NS & NS \\
\hline $18: 1 n-9$ & $6 \cdot 32$ & 3.07 & 6.54 & 3.77 & 3.73 & 1.56 & 7.38 & 2.43 & 6.57 & $4 \cdot 19$ & 4.74 & 1.71 & NS & $<0.05$ & NS \\
\hline $18: 1 n-7$ & $1 \cdot 18$ & 0.39 & 1.33 & 0.63 & 0.898 & 0.216 & 0.684 & 0.159 & 0.808 & 0.411 & 0.585 & 0.099 & $<0.001$ & NS & NS \\
\hline PUFA & 7.98 & 2.7 & $7 \cdot 77$ & $2 \cdot 18$ & $7 \cdot 11$ & 1.00 & $10 \cdot 3$ & $2 \cdot 4$ & 8.25 & 3.47 & 8.98 & 2.07 & $<0.05$ & NS & NS \\
\hline $18: 2 n-6$ & 3.86 & 1.31 & 3.39 & 0.99 & 2.56 & 0.41 & $5 \cdot 1$ & 1.5 & 3.83 & 1.75 & $3 \cdot 8$ & 0.84 & $<0.01$ & $<0.05$ & NS \\
\hline $20: 3 n-6$ & 0.128 & 0.033 & 0.149 & 0.118 & 0.095 & 0.044 & 0.133 & 0.103 & 0.072 & 0.053 & 0.053 & 0.046 & NS & NS & NS \\
\hline $20: 4 n-6$ & 1.99 & 0.38 & 2.01 & 0.38 & 1.05 & 0.52 & $2 \cdot 41$ & 0.62 & $2 \cdot 12$ & 1.0 & $1 \cdot 11$ & 0.19 & NS & $<0.001$ & NS \\
\hline $20: 5 n-3$ & 0.040 & 0.038 & 0.032 & 0.031 & 0.212 & 0.077 & 0.067 & 0.047 & 0.033 & 0.035 & 0.216 & 0.035 & NS & $<0.001$ & NS \\
\hline $22: 5 n-3$ & 0.281 & 0.085 & 0.269 & 0.086 & 0.303 & 0.059 & 0.324 & 0.107 & 0.367 & 0.184 & 0.236 & 0.061 & NS & NS & NS \\
\hline $22: 6 n-3$ & 1.46 & 0.81 & 1.54 & 0.82 & 2.73 & 0.55 & 1.97 & 0.55 & 1.53 & 0.83 & 3.35 & 1.51 & NS & $<0.001$ & NS \\
\hline$n-6$ PUFA & 6.07 & 1.76 & $5 \cdot 76$ & 1.34 & $3 \cdot 78$ & 0.91 & 7.82 & 1.96 & $6 \cdot 14$ & $2 \cdot 68$ & 5.00 & 0.93 & $<0.05$ & $<0.001$ & NS \\
\hline$n-3$ PUFA & 1.87 & 0.9 & 1.95 & 0.96 & $3 \cdot 29$ & 0.59 & $2 \cdot 48$ & 0.63 & 2.09 & 1.07 & 3.96 & 1.44 & NS & $<0.001$ & NS \\
\hline$\Delta 9$-Desaturase index $\ddagger$ & 0.228 & 0.092 & 0.227 & 0.126 & 0.199 & 0.056 & 0.062 & 0.011 & 0.069 & 0.034 & 0.063 & 0.018 & $<0.0001$ & NS & NS \\
\hline$\Delta 6$-Desaturase index§ & 0.035 & 0.009 & 0.053 & 0.024 & 0.037 & 0.014 & 0.03 & 0.034 & 0.028 & 0.012 & 0.023 & 0.005 & $<0.05$ & NS & NS \\
\hline$\Delta 5$-Desaturase index $\|$ & $16 \cdot 0$ & 3.5 & $14 \cdot 1$ & 4.2 & 11.3 & $2 \cdot 1$ & 24.0 & 8.7 & $24 \cdot 2$ & $7 \cdot 1$ & $14 \cdot 1$ & 1.4 & $<0.001$ & $<0.002$ & NS \\
\hline UI & 126 & 14 & 128 & 27 & 162 & 21 & 154 & 14 & 129 & 34 & 170 & 34 & NS & $<0.001$ & NS \\
\hline $\mathrm{PI}$ & 66.9 & 12.2 & 69.9 & 26.4 & 102.7 & $20 \cdot 3$ & 87.4 & $12 \cdot 9$ & 74.1 & $32 \cdot 1$ & $108 \cdot 7$ & 31.3 & NS & $<0.001$ & NS \\
\hline
\end{tabular}

$\mathrm{UI}$, unsaturation index; PI, peroxidation index.

expressed as $\mathrm{mg} \mathrm{FA} / \mathrm{g}$ skeletal muscle.

†A two-way ANOVA was used, followed by Fisher's multiple comparison test. When there was an interaction, a one-way ANOVA followed by Fisher's multiple comparison test was conducted on the $5 \%$ diet groups and the $30 \%$ diet groups distinctly.

(S)-Desaturase index $=16: 1 n-7 / 16: 0$.

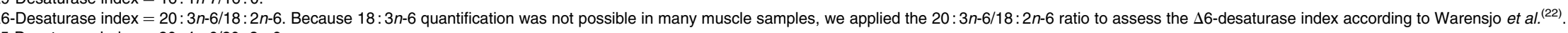
$\Delta 5$-Desaturase index $=20: 4 n-6 / 20: 3 n-6$. 

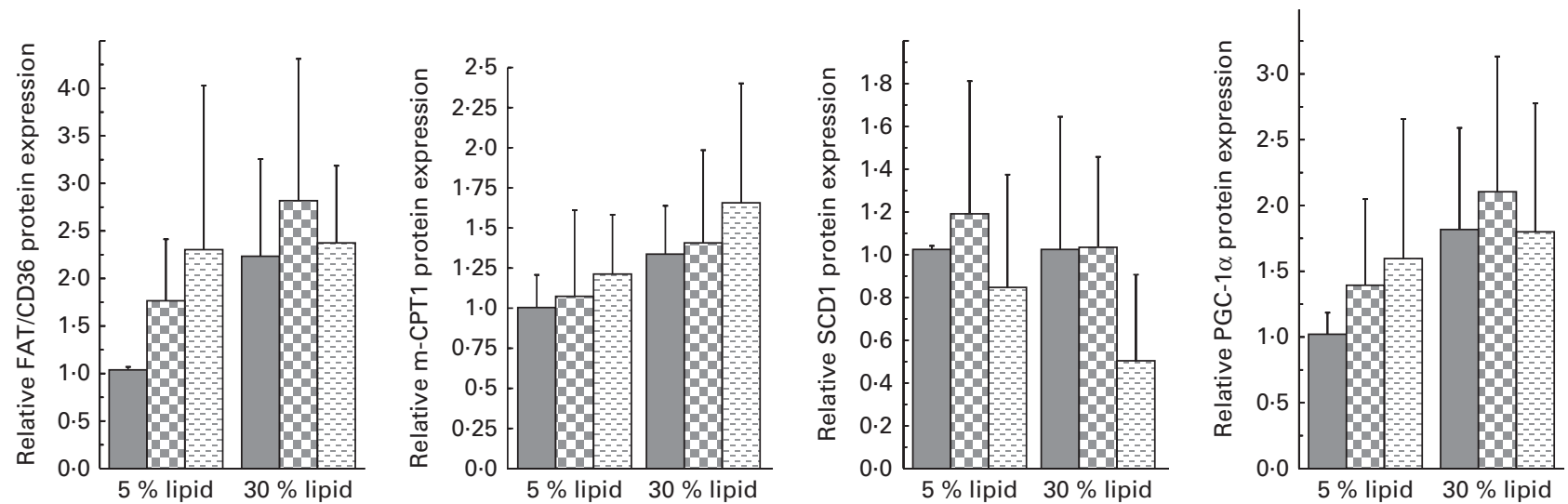

Fig. 4. Muscle protein expression of fatty acid translocase/cluster of differentiation 36 (FAT/CD36), muscle carnitine palmitoyltransferase 1 (m-CPT1), stearoylCoA desaturase 1 (SCD1) and PPAR $\gamma$ co-activator $1 \alpha$ (PGC-1 $\alpha$ ). Western blot was performed on protein extracts from the muscle of rats, using anti-FAT/CD36, anti-m-CPT1, anti-SCD1 and anti-PGC- $1 \alpha$ antibodies. Anti- $\beta$-actin antibody was used to confirm equal loading. Western blot was quantified using Image J software $(\mathrm{NIH})$. Values are means $(n 6-8)$, with standard deviations represented by vertical bars. There was a significant effect of lipid quantity on FAT/CD36 protein expression $(P<0.05)$ or almost significant effect on m-CPT1 $(P=0.051)$ and PGC-1 $\alpha$ protein expression $(P=0.053)$. There was a nearly significant effect of lipid quality on SCD1 protein expression $(P=0.059)$ (fish oil $v$. mixed and lard diets. $\square$, Basal diet; $\square$, lard-rich diet; 圆, fish oil-rich diet.

decreased in the liver of rats fed the $30 \%$ lipid diets, except in the liver of those fed the $30 \%$ lard diet. Both $\beta$-HAD activity and the protein expression of FATP 4 were increased with the lard $30 \%$ lipid diet, while they were decreased or tended to decrease with the other two $30 \%$ lipid diets. It has been proposed that FATP 4 is important as a lipid transport protein directing lipids for lipid oxidation in muscle ${ }^{(32)}$, and the present results suggest that FATP 4 may also be important to direct FA towards $\beta$-oxidation in the liver. A deregulation of mitochondrial function may be implicated in liver fat accumulation observed with the $30 \%$ lipid diets, where mitochondrial $\beta$-oxidation (measured by the gene expression of MCAD and $\beta$-HAD activity) was decreased. The intake of the $30 \%$ lipid diets led to a higher supply with energy substrates and this may be responsible for the decrease in $\beta$-HAD activity with the $30 \%$ lipid diets, except with the lard diet where $\beta$-oxidation remained high, probably to allow a high-rate oxidation of the saturated 'toxic' FA from this diet.

Oxidative stress, an important component of NAFLD, plays a role in the progression of liver steatosis to non-alcoholic steatohepatitis. Interestingly, lipid peroxidation and protein oxidation were increased in rats fed the 30\% lipid diets. These results may reflect an increase in mitochondrial reactive oxygen species production in the liver of rats with hepatic steatosis, despite lower mitochondriogenesis and $\beta$-oxidation activities. Moreover, the other important result of the present study is that lipid peroxidation was highly increased with the fish-oil diet. Within the 5\% lipid diets, the liver TBARS level was increased by $22 \%$ with the fish-oil diet compared with the mixed diet, whereas within the $30 \%$ lipid diets, the liver TBARS level was increased by $104 \%$ with the fish-oil diet compared with the mixed diet. It is known that unsaturated FA are preferable substrates for lipid peroxidation, and, in fact, liver TBARS levels were positively correlated with the liver $n$-3:PUFA ratio and the PI. In a previous work, it has also been reported that a high intake of DHA increased, in a dose-dependent way, liver lipid peroxidation in rabbits, where the highest tested dose was 1\% DHA of energy intake $^{(33)}$. Moreover, oxidative stress and mitochondrial dysfunction may lead to large hepatocyte injury, inflammation and fibrosis ${ }^{(2,3)}$. Therefore, the fatty liver from the rats fed the fish-oil diet may be prone to the transformation of liver steatosis into non-alcoholic steatohepatitis.

As expected, muscle FA content partly mirrored the quality of the FA in the studied diets, with more SFA in the muscle of rats fed the lard diet and more $n-3$ FA in the muscle of rats fed the fish-oil diet. In line with this observation, previous studies have also reported that the FA composition of muscle lipids is influenced by the type of FA in the administered diet ${ }^{(34,35)}$. However, the long-term intake of the $30 \%$ lipid diets did not modify the muscle TAG content in the present study, but had an impact on the desaturase indices. Although it is known that PUFA decrease and SFA increase the expression of SCD1 in the liver ${ }^{(36)}$, there are few data describing SCD1 regulation by dietary $\mathrm{FA}$ in skeletal muscle ${ }^{(34)}$. In a previous work $^{(37)}$, we observed an elevated SCD1 index to be associated with increased fat accumulation in skeletal muscle. In this work, the SCD1 index, calculated as the $\Delta 9$-desaturase index, was sharply decreased with the $30 \%$ lipid diets. While the activity of SCD1 was not modified by the quality of the diet, the protein expression of SCD1 was almost decreased with the fish-oil diet. The $\Delta 6$-desaturase index was also decreased in rats fed the $30 \%$ lipid diets compared with those fed the $5 \%$ lipid diets. As in the liver, the muscle $\Delta 5$-desaturase index was decreased with the $n$ - 3 diet, showing a systemic effect of the $n-3$ diet on different tissues.

In skeletal muscle, PGC- $1 \alpha$ is known to stimulate mitochondrial biogenesis via the co-activation of nuclear respiratory factor 1 , to regulate genes involved in oxidative phosphorylation and to co-activate the PPAR, thereby regulating the pathways of lipid metabolism ${ }^{(29)}$. We observed that the protein expressions of both PGC- $1 \alpha$ and m-CPT1 were almost significantly increased with the $30 \%$ lipid diets, with both PGC- $1 \alpha$ and $\mathrm{m}-\mathrm{CPT} 1$ being regulated by PPAR- $\delta$ in the muscle ${ }^{(38)}$. 
Similarly, increased mitochondriogenesis had been previously reported with a high-fat diet ${ }^{(39)}$. In contrast, in a previous work $^{(37)}$, we observed that the gene expression of $P G C-1 \alpha$ was down-regulated by a high-fat/high-sucrose diet, and some authors have demonstrated that palmitic acid or high SFA down-regulate the mRNA expression of PGC- $1 \alpha^{(40)}$. In parallel to the increase in the protein expression of PGC- $1 \alpha$ with the $30 \%$ lipid diets, we observed an increase in the protein expression of FAT/CD36. However, the protein or gene expressions of other transporters such as FATP 4 and FABP3 were not modified. It has been demonstrated that the promoter of FAT/CD36 has a PPAR response element sequence ${ }^{(41)}$; therefore, an increased protein expression of PGC- $1 \alpha$ could result in an enhanced protein expression of FAT/CD36, as has been reported already, while the gene or protein expressions of other FA transporters were not modified $^{(42)}$. The present results are in favour of an increased uptake of FA with the $30 \%$ lipid diets and in favour of an activation of muscle oxidative metabolism that prevented the accumulation of lipids in the muscle.

We observed that the AUC of the OGTT was positively correlated with the muscle SFA levels and negatively correlated with the muscle $n$-3:PUFA ratio. This observation was not surprising as several studies in animals have demonstrated a differential impairment in the degree of insulin sensitivity, after feeding with a saturated fat diet or $n-6$ or $n-3$ polyunsaturated fat diets ${ }^{(43)}$. In the present study, only the rats fed the lard 30\% lipid diet were insulin resistant. So, it was probably the modification of the FA composition in the muscle cell membrane that led to IR rather than the modification of the lipid content in the muscle.

Lipid peroxidation and protein oxidation were not modified in the muscle of rats fed the $30 \%$ lipid diets, while total GSH was decreased and catalase activity was increased. These results, associated with the probable activation of muscle oxidative metabolism, might reflect increased mitochondrial reactive oxygen species production that was counteracted by the antioxidant systems. Moreover, muscle TBARS levels were positively correlated with the muscle $n$-3:PUFA ratio and the peroxidisation index. This means that the muscle from the rats fed the fish-oil diet, as in the case of the liver, may be more prone to oxidative injury. However, with the fish-oil $30 \%$ lipid diet, catalase activity was increased, once again probably to protect the cells against $\mathrm{H}_{2} \mathrm{O}_{2}$ and the oxidation of membrane phospholipids.

In conclusion, we examined in the present study the impact of fat quantity and quality on liver and muscle metabolism in an integrated fashion. The present results demonstrated that high lipid intake differently influenced the rat liver and muscle lipid utilisation and their FA composition. In the liver, lipogenesis was markedly reduced with the $30 \%$ lipid diets to prevent liver lipid accumulation, whereas mitochondriogenesis was decreased, maybe to limit mitochondrial reactive oxygen species overproduction, and finally led to liver lipid accumulation and peroxidation. On the contrary, the muscle uptake of FA from the $30 \%$ lipid diets was increased, but the high activation of muscle oxidative metabolism tended to prevent the accumulation of lipids in the muscle. The lard diet led to the development of IR, without an increase in the muscle lipid content, pointing out that the lipid quality (such as ceramides) and the FA composition of the muscle modulated insulin sensitivity rather than the tissue lipid accumulation itself. The fish-oil diet failed to prevent hepatic steatosis and the high level of PUFA in this diet made the tissues more prone to oxidation, and thus there is a risk for the transformation of liver steatosis into non-alcoholic steatohepatitis. These results clearly show that the dietary intake of SFA should be reduced, and precaution should be taken when advising a high unphysiological intake of PUFA-rich products such as fish oils.

\section{Supplementary material}

To view supplementary material for this article, please visit http://dx.doi.org/10.1017/S0007114513001311

\section{Acknowledgements}

The authors acknowledge Drs Alain Grynberg and Délphine Rousseau (INRA, Paris) for their assistance, whose advices were important for diet conception and preparation. The authors also thank the staff of the animal facilities for animal use. The present study received no specific grant from any funding agency in the public, commercial or not-for-profit sectors.

C. F.-C. and C. C. designed the research; C. F.-C., M. A., G. F., B. B. and J. R. conducted the research, C. F.-C., M. A., F. C., J. P. C. and C. C. analysed the data; C. F.-C. wrote the paper and had responsibility for the final content. All the authors read and approved the final manuscript.

The authors declare that there is no conflict of interest.

\section{References}

1. Misra A, Singhal N \& Khurana L (2010) Obesity, the metabolic syndrome, and type 2 diabetes in developing countries: role of dietary fats and oils. J Am Coll Nutr 29, 289S-301S.

2. Cave M, Deaciuc I, Mendez C, et al. (2007) Nonalcoholic fatty liver disease: predisposing factors and the role of nutrition. J Nutr Biochem 18, 184-195.

3. Mantena SK, King AL, Andringa KK, et al. (2008) Mitochondrial dysfunction and oxidative stress in the pathogenesis of alcohol- and obesity-induced fatty liver diseases. Free Radic Biol Med 44, 1259-1272.

4. Shapiro H, Tehilla M, Attal-Singer J, et al. (2011) The therapeutic potential of long-chain omega-3 fatty acids in nonalcoholic fatty liver disease. Clin Nutr 30, 6-19.

5. Abbott SK, Else PL, Atkins TA, et al. (2012) Fatty acid composition of membrane bilayers: importance of diet polyunsaturated fat balance. Biochim Biophys Acta 1818, 1309-1317.

6. Kraegen EW, James DE, Storlien LH, et al. (1986) In vivo insulin resistance in individual peripheral tissues of the high fat fed rat: assessment by euglycaemic clamp plus deoxyglucose administration. Diabetologia 29, 192-198.

7. Manco M, Mingrone G, Greco AV, et al. (2000) Insulin resistance directly correlates with increased saturated fatty acids in skeletal muscle triglycerides. Metabolism 49, 220-224. 
8. Poudyal H, Panchal SK, Diwan V, et al. (2011) Omega-3 fatty acids and metabolic syndrome: effects and emerging mechanisms of action. Prog Lipid Res 50, 372-387.

9. Smith DA (2012) Omega-3 polyunsaturated fatty acid supplements do not reduce major cardiovascular events in adults. Ann Intern Med 157, JC6-5.

10. Hill JO, Peters JC, Lin D, et al. (1993) Lipid accumulation and body fat distribution is influenced by type of dietary fat fed to rats. Int J Obes Relat Metab Disord 17, 223-236.

11. Buettner R, Parhofer KG, Woenckhaus M, et al. (2006) Defining high-fat-diet rat models: metabolic and molecular effects of different fat types. J Mol Endocrinol 36, 485-501.

12. Parker HM, Johnson NA, Burdon CA, et al. (2012) Omega-3 supplementation and non-alcoholic fatty liver disease: a systematic review and meta-analysis. J Hepatol 56, 944-951.

13. Gomez-Perez Y, Amengual-Cladera E, Catala-Niell A, et al. (2008) Gender dimorphism in high-fat-diet-induced insulin resistance in skeletal muscle of aged rats. Cell Physiol Biochem 22, 539-548.

14. Aoun M, Fouret G, Michel F, et al. (2012) Dietary fatty acids modulate liver mitochondrial cardiolipin content and its fatty acid composition in rats with non alcoholic fatty liver disease. J Bioenerg Biomembr 44, 439-452.

15. Bradford MM (1976) A rapid and sensitive method for the quantitation of microgram quantities of protein utilizing the principle of protein-dye binding. Anal Biochem $\mathbf{7 2}$, 248-254.

16. Yang SY, He XY \& Schulz H (2005) 3-Hydroxyacyl-CoA dehydrogenase and short chain 3-hydroxyacyl-CoA dehydrogenase in human health and disease. FEBS $J \mathbf{2 7 2}$, $4874-4883$.

17. Feillet-Coudray C, Sutra T, Fouret G, et al. (2009) Oxidative stress in rats fed a high-fat high-sucrose diet and preventive effect of polyphenols: involvement of mitochondrial and NAD(P)H oxidase systems. Free Radic Biol Med $\mathbf{4 6}$, 624-632.

18. Aoun M, Michel F, Fouret G, et al. (2010) A polyphenol extract modifies quantity but not quality of liver fatty acid content in high-fat-high-sucrose diet-fed rats: possible implication of the sirtuin pathway. BrJ Nutr 104, 1760-1770.

19. Folch J, Lees M \& Sloane Stanley GH (1957) A simple method for the isolation and purification of total lipides from animal tissues. J Biol Chem 226, 497-509.

20. Bartlett GR (1959) Phosphorus assay in column chromatography. J Biol Chem 234, 466-468.

21. Warensjo E, Ohrvall M \& Vessby B (2006) Fatty acid composition and estimated desaturase activities are associated with obesity and lifestyle variables in men and women. Nutr Metab Cardiovasc Dis 16, 128-136.

22. Warensjo E, Riserus U, Gustafsson IB, et al. (2008) Effects of saturated and unsaturated fatty acids on estimated desaturase activities during a controlled dietary intervention. Nutr Metab Cardiovasc Dis 18, 683-690.

23. Pietrangelo A, Grandi R, Tripodi A, et al. (1990) Lipid composition and fluidity of liver mitochondria, microsomes and plasma membrane of rats with chronic dietary iron overload. Biochem Pharmacol 39, 123-128.

24. Hu ML, Frankel EN \& Leibovitz BE (1989) Effect of dietary lipids and vitamin $\mathrm{E}$ on in vitro lipid peroxidation in rat liver and kidney homogenates. J Nutr 119, 1574-1582.

25. Lamaziere A, Wolf C \& Barbe U (2013) Lipidomics of hepatic lipogenesis inhibition by omega 3 fatty acids. Prostaglandins Leukot Essent Fatty Acids 88, 149-154.

26. Dobrzyn A \& Ntambi JM (2005) The role of stearoyl-CoA desaturase in the control of metabolism. Prostaglandins Leukot Essent Fatty Acids 73, 35-41.
27. Nickerson JG, Alkhateeb H, Benton CR, et al. (2009) Greater transport efficiencies of the membrane fatty acid transporters FAT/CD36 and FATP 4 compared with FABPpm and FATP1 and differential effects on fatty acid esterification and oxidation in rat skeletal muscle. J Biol Chem 284, 16522-16530.

28. Jump DB \& Clarke SD (1999) Regulation of gene expression by dietary fat. Annu Rev Nutr 19, 63-90.

29. Lin J, Handschin C \& Spiegelman BM (2005) Metabolic control through the PGC-1 family of transcription coactivators. Cell Metab 1, 361-370.

30. Lehman JJ, Barger PM, Kovacs A, et al. (2000) Peroxisome proliferator-activated receptor gamma coactivator-1 promotes cardiac mitochondrial biogenesis. J Clin Invest 106, $847-856$.

31. Kerner J \& Hoppel C (2000) Fatty acid import into mitochondria. Biochim Biophys Acta 1486, 1-17.

32. Jeppesen J, Jordy AB, Sjoberg KA, et al. (2012) Enhanced fatty acid oxidation and FATP 4 protein expression after endurance exercise training in human skeletal muscle. PLOS ONE 7, e29391.

33. Gladine C, Roy NC, Rigaudière JP, et al. (2012) Increasing intake of long-chain $n-3$ PUFA enhances lipoperoxidation and modulates hepatic gene expression in a dose-dependent manner. Br J Nutr 107, 1254-1273.

34. Lee JS, Pinnamaneni SK, Eo SJ, et al. (2006) Saturated, but not $n-6$ polyunsaturated, fatty acids induce insulin resistance: role of intramuscular accumulation of lipid metabolites. J Appl Physiol 100, 1467-1474.

35. Abbott SK, Else PL \& Hulbert AJ (2010) Membrane fatty acid composition of rat skeletal muscle is most responsive to the balance of dietary $n-3$ and n-6 PUFA. Br J Nutr 103, 522-529.

36. Ntambi JM (1999) Regulation of stearoyl-CoA desaturase by polyunsaturated fatty acids and cholesterol. J Lipid Res $\mathbf{4 0}$, 549-558.

37. Aoun M, Michel F, Fouret G, et al. (2011) A grape polyphenol extract modulates muscle membrane fatty acid composition and lipid metabolism in high-fat-high-sucrose diet-fed rats. Br J Nutr 106, 491-501.

38. Dressel U, Allen TL, Pippal JB, et al. (2003) The peroxisome proliferator-activated receptor beta/delta agonist, GW501516, regulates the expression of genes involved in lipid catabolism and energy uncoupling in skeletal muscle cells. Mol Endocrinol 17, 2477-2493.

39. Gomez-Perez Y, Capllonch-Amer G, Gianotti M, et al. (2012) Long-term high-fat-diet feeding induces skeletal muscle mitochondrial biogenesis in rats in a sex-dependent and muscle-type specific manner. Nutr Metab (Lond) 9, 15.

40. Coll T, Jové M, Rodríguez-Calvo R, et al. (2006) Palmitatemediated downregulation of peroxisome proliferatoractivated receptor-gamma coactivator-1alpha in skeletal muscle cells involves MEK1/2 and nuclear factor-kappaB activation. Diabetes 55, 2779-2787.

41. Teboul L, Febbraio M, Gaillard D, et al. (2001) Structural and functional characterization of the mouse fatty acid translocase promoter: activation during adipose differentiation. Biochem J 360, 305-312.

42. Choi CS, Befroy DE, Codella R, et al. (2008) Paradoxical effects of increased expression of PGC-1alpha on muscle mitochondrial function and insulin-stimulated muscle glucose metabolism. Proc Natl Acad Sci U S A 105, 19926-19931.

43. Galgani JE, Uauy RD, Aguirre CA, et al. (2008) Effect of the dietary fat quality on insulin sensitivity. Br J Nutr 100, 471-479. 